\title{
Kidney Carcinoma Ovarian Metastasis: Review of the Literature
}

\author{
Nektarios Koufopoulos $^{1}$, Despoina Nasi ${ }^{2}$, Foteini Antoniadou ${ }^{1}$, Stefania Kokkali ${ }^{3}$, Stamatios Theocharis ${ }^{4}$ \\ 1. Department of Pathology, "Saint Savvas" Cancer Hospital, Athens, GRC 2. Department of Oncology, "Saint Savvas" \\ Cancer Hospital, Athens, GRC 3. Department of Oncology, "Saint Savvas" Cancer Hospital, Athens, GRC 4. Department \\ of Pathology, National and Kapodistrian University of Athens, Athens, GRC
}

Corresponding author: Nektarios Koufopoulos, koufonektar@yahoo.com
Received 10/31/2018

Review began 11/13/2018

Review ended 11/18/2018

Published 11/21/2018

\section{๑) Copyright 2018}

Koufopoulos et al. This is an open access article distributed under the terms of the Creative Commons Attribution License CC-BY 3.0., which permits unrestricted use, distribution, and reproduction in any medium, provided the original author and source are credited.

\begin{abstract}
Ovarian metastasis is common with secondary tumors representing up to $15 \%$ of ovarian neoplasms. The malignancies most commonly involving the ovaries are carcinomas of the stomach, colon, breast, endocervix, endometrium, and lymphoma. Secondary ovarian involvement by kidney carcinoma occurs very rarely and is usually associated with widespread dissemination.
\end{abstract}

We conducted a review of kidney carcinoma with ovarian metastasis in the literature using the keywords clear cell renal cell carcinoma, papillary renal cell carcinoma, chromophobe renal cell carcinoma collecting duct carcinoma, and ovarian metastasis on Google Scholar and PubMed indices in April 2018, including a case diagnosed in our department. To date, 30 articles presenting 41 cases of kidney carcinoma with ovarian metastasis are reported in the literature. All reviewed cases were analyzed for diagnosis, surgical and systemic therapy, and outcome.

Diagnosis may sometimes be challenging, requiring appropriate immunohistochemical markers in difficult cases. A combination of surgery and adjuvant therapy offers significant benefit in disease control or palliation of symptoms. Due to inconsistency in the reported data, further studies are needed to make safe conclusions regarding survival.

Categories: Obstetrics/Gynecology, Pathology, Oncology

Keywords: clear cell renal cell carcinoma, papillary renal cell carcinoma, chromophobe renal cell carcinoma, collecting duct carcinoma, metastasis, ovary

\section{Introduction And Background}

Metastasis to the ovaries is common, and secondary tumors represent $7 \%$ to $15 \%$ of the ovarian neoplasms [1]. The most common malignancies responsible for the secondary involvement of the ovaries include stomach, colon, breast, endocervix, endometrium, as well as lymphoma [2]. In many cases, a known history of a primary neoplasm exists, but the ovarian mass is rarely the initial lesion [3].

Among the different types of kidney carcinomas (KC), clear cell renal cell carcinoma (ccRCC) is the most common histotype. It usually metastasizes to the lungs, lymph nodes, bones, brain, liver [2], and, very rarely, the ovary. According to our knowledge, fewer than 40 cases have been published in the English literature to date.

Papillary renal cell carcinoma (PRCC) and chromophobe renal cell carcinoma (ChRCC) account for 10\% and $5 \%$ of the KC cases, respectively. They display an indolent behavior, remaining confined to the kidney [4], while collecting duct carcinoma (CDC) [5] and unclassified renal cell carcinoma (RCCU) [6] are rare tumors with aggressive clinical behavior.

Using the keywords clear cell renal cell carcinoma, papillary renal cell carcinoma, chromophobe renal cell carcinoma collecting duct carcinoma, and ovarian metastasis, we reviewed reports of KC with ovarian metastasis via Google Scholar and PubMed indices in April 2018, including a case diagnosed in our department. Herein, we have reviewed the clinicopathological features, treatment, and outcome of the 41 $\mathrm{KC}$ cases with ovarian metastasis yielded by our search.

\section{Review}

KC metastasis to the ovary is a rare event. This can be explained by its male predominance with the male-tofemale ratio being 2:1 [7], low incidence of tumor emboli to the ovary, vascular sclerosis of the postmenopausal ovary when KC usually occurs, and the misdiagnoses of some metastatic tumors as primary ovarian neoplasms [8-9].

In the literature, several $\mathrm{KC}$ cases were not completely analyzed, with important data missing such as the 
type of surgical operation, adjuvant therapy, and sizes of the primary and metastatic tumors. The clinicopathological features of the cases, 36 ccRCC, two PRCC, one CDC, one ChRCC, and one RCCU, are presented in Table 1. Patients' age ranged from 17 to 80 years (mean age: 53 years). The right kidney was involved in 20 and the left in 19 patients. Ovarian metastasis was ipsilateral in 13, contralateral in 15, and bilateral in 11 cases, including our case. According to the available data, primary tumor size ranged from 50 $\mathrm{mm}$ to $165 \mathrm{~mm}$ (mean value: $86 \mathrm{~mm}$ ), whereas the size of the secondary tumor ranged from microscopic involvement to $180 \mathrm{~mm}$ (mean value: $100 \mathrm{~mm}$ ). In two cases, there was tumor-to-tumor metastasis consisting of two small nodules in a mucinous cystadenoma [10] in the first case and a multilocular cystic ovarian tumor consisting of mixed mucinous cystadenoma and Brenner tumor in the second one [11].

\begin{tabular}{|c|c|c|c|c|c|c|c|c|}
\hline Year & Age & Type & Kidney & Ovary & Surgery & S.A.Th. & Outcome(mo) & Author \\
\hline 1949 & 57 & ccRCC & Left & Left & NA & No & DOD (18) & Martzlof et al. [12] \\
\hline 1957 & 64 & ccRCC & Right & Bilateral & BSO & No & DOD (15) & Hobbs et al. [13] \\
\hline 1981 & 68 & ccRCC & Right & Left & LO & No & ANED (25) & Stefani et al. [14] \\
\hline 1983 & 52 & ccRCC & Left & Left & NA & No & Unknown & Buller et al. [15] \\
\hline 1992 & 48 & ccRCC & Right & Left & LSO & No & AWD (96) & Young et al. [16] \\
\hline 1992 & 62 & ccRCC & Left & Right & HBSO & No & AWD (6) & Young et al. [16] \\
\hline 1992 & 48 & ccRCC & Left & Left & LSO & No & NA & Young et al. [16] \\
\hline 1992 & 28 & ccRCC & Right & Left & NA & NA & NA & Liu et al. [17] \\
\hline 1993 & 40 & ccRCC & Left & Bilateral & HBSO & No & AWD (55) & Spencer et al. [18] \\
\hline 1994 & 46 & ccRCC & Left & Bilateral & HBSO & Yes & ANED (36) & Adachi et al. [19] \\
\hline 1996 & 54 & ccRCC & Right & Left & NA & No & NA & Fields et al. [8] \\
\hline 1998 & 80 & ccRCC & Right & Bilateral & HBSO & No & ANED (24) & Vara et al. [20] \\
\hline 2003 & 48 & ccRCC & Left & Bilateral & HBSO & Yes & AWD (3) & Hammock et al. [21] \\
\hline 2003 & 50 & ccRCC & Right & Right & HBSO & No & ANED (6) & Insabato et al. [10] \\
\hline 2003 & 49 & ccRCC & Right & NA & NA & No & DOD (6) & Insabato et al. [10] \\
\hline 2003 & 17 & ccRCC & Left & Left & NA & No & ANED (24) & Insabato et al. [10] \\
\hline 2004 & 61 & ccRCC & Left & Bilateral & BSO & Yes & AWD (24) & Valappil et al. [22] \\
\hline 2004 & 79 & CDC & Left & Left & No & No & DOD $(<1)$ & Kassouf et al. [23] \\
\hline 2006 & 52 & ccRCC & Left & Right & BSO & Yes & DOD (10) & Kato et al. [24] \\
\hline 2007 & 73 & PRCC & Right & Left & LSO & NA & NA & Stolnicu et al. [25] \\
\hline 2009 & 56 & ccRCC & Right & Bilateral & HBSO & No & ANED (19) & Albrizio et al. [26] \\
\hline 2009 & 45 & ccRCC & Right & Left & LO & Yes & AWD (48) & Anagnostou et al. [27] \\
\hline 2009 & 54 & ccRCC & Left & Left & HBSO & No & DOD (9) & Toquero et al. [7] \\
\hline 2010 & 54 & ccRCC & NA & Bilateral & HBSO & Yes & AWD (48) & Guney et al. [28] \\
\hline 2011 & 63 & ccRCC & Right & NA & HBSO & No & AWD (132) & Decoene et al. [29] \\
\hline 2012 & 45 & ccRCC & Left & Right & HBSO & Yes & NA & Udoji et al. [30] \\
\hline 2012 & 71 & ccRCC & Right & Right & RSO & No & NA & Ibrahim et al. [11] \\
\hline 2014 & 61 & ccRCC & Right & Bilateral & HBSO & Yes & ANED (12) & Bauerová et al. [31] \\
\hline 2015 & 55 & ccRCC & Left & Left & HBSO & No & ANED (14) & Dolanbay et al. [32] \\
\hline 2015 & 51 & ccRCC & Left & Right & HBSO & No & ANED (2) & Kostrzewa et al. [9] \\
\hline 2015 & 48 & ccRCC & Right & Right & HBSO & No & NA & Bohara et al. [33] \\
\hline 2016 & 60 & ccRCC & Right & Right & NA & ${ }^{*}$ & AWD (40) & Liang et al. [34] \\
\hline
\end{tabular}




\section{Cureus}

$\begin{array}{|lllllllll|}2016 & 48 & \text { ccRCC } & \text { Left } & \text { Right } & \text { NA } & * & \text { AWD (57) } & \text { Liang et al. [34] } \\ 2016 & 45 & \text { ccRCC } & \text { Right } & \text { Left } & \text { NA } & * & \text { DOD (48) } & \text { Liang et al. [34] } \\ 2016 & 43 & \text { ccRCC } & \text { Right } & \text { Right } & \text { NA } & * & \text { DOD (109) } & \text { Liang et al. [34] } \\ 2016 & 52 & \text { ccRCC } & \text { Left } & \text { Right } & \text { NA } & * & \text { DOD (132) } & \text { Liang et al. [34] } \\ 2016 & 52 & \text { ccRCC } & \text { Right } & \text { Left } & \text { NA } & * & \text { DOD (204) } & \text { Liang et al. [34] } \\ 2016 & \text { NA } & \text { ChRRC } & \text { xxx } & \text { NA } & \text { NA } & * & \text { NA } & \text { Liang et al. [34] } \\ 2016 & 37 & \text { RCCU } & \text { Left } & \text { Bilateral } & \text { NA } & * & \text { AWD (22) } & \text { Liang et al. [34] } \\ 2017 & 45 & \text { PRCC } & \text { Left } & \text { Left } & \text { HBSO } & \text { No } & \text { ANED (3) } & \text { Bashkar et al. [35] } \\ 2017 & 46 & \text { ccRCC } & \text { Right } & \text { Bilateral } & \text { HBSO } & \text { Yes } & \text { DOD (7) } & \text { Koufopoulos et al. [36] }\end{array}$

\section{TABLE 1: Kidney carcinoma clinicopathological characteristics}

NA: not available, SATh: systemic adjuvant therapy, HBSO: hysterectomy and bilateral salpingo-oophorectomy, BSO: bilateral salpingooophorectomy, RSO: right salpingo-oophorectomy, LSO: left salpingo-oophorectomy, LO: left oophorectomy, DOD: died of disease, AWD: alive with disease, ANED: alive no evidence of disease, ccRCC: clear cell renal cell carcinoma, ChRRC: chromophobe renal cell carcinoma, CDC: collecting duct carcinoma, PRCC: papillary renal cell carcinoma, RCCU: renal cell carcinoma unclassified.

${ }^{*}$ Four patients in the Liang et al. series received chemotherapy. No more details were provided.

Regarding the presenting symptoms, 11 patients were asymptomatic with metastasis found on scheduled postoperative imaging. Seven patients presented with an abdominal mass [7,8,10,16,22,32], four with weight loss $[7,11,13,34]$, three with vaginal bleeding [10,12,19], two with fever [14,20], two with irregular menses $[18,21]$, two with an abdominal distension [11,26], two with ascites [8,15], abdominal pain [20,36], weight gain [15], fatigue [13], weakness [14], shortness of breath [8,36], pelvic pain [26], generalized malaise and decreased energy [30], flank pain [34], bone fracture [24], and thyroid metastasis [16]. In 26 patients, ovarian metastases were detected three months to 21 years after kidney involvement. In six cases, the primary cancer site and the metastasis were discovered concomitantly, while in four cases, the metastasis was detected first. In one case, ovarian metastasis was detected eight years before the primary tumor [12]. Fuhrman grade was mentioned in 11 cases, including our case, four of them being grade 2 , six grade 3 , and a single case grade 4 with sarcomatoid features [7,24,29,30,33-34].

Clinical features such as cyst formation, size, and bilaterality did not help in differentiating primary from metastatic ovarian tumors [37]. Histologically, the main differential diagnosis of metastatic ccRCC to the ovary was between ovarian clear cell carcinoma (OCCC), steroid cell tumor, dysgerminoma, and clear cell variant of struma ovarii [10,21]. In cases of simultaneous presentation of kidney and ovarian tumor, ovarian metastasis to kidney and independent primaries have to be considered. There are three cases with independent primaries [31] and four ovarian carcinomas metastatic to the kidney [9] in the literature. Attention to histological differences between ccRCC and its ovarian mimics paired with clinical history were considered sufficient on several occasions.

Microscopically, both ccRCC and OCCC may have cystic, solid, tubular, and papillary areas. Tumor cells may display clear or eosinophilic cytoplasm and prominent nucleoli. In ccRCC, tumor cells usually lack significant pleomorphism (Figure 1a) and are characteristically associated with a prominent vascular network (Figure $1 b$ ) $[18,22]$. In OCCC, tubular or glandular formations are lined by hobnail cells at least focally in almost $90 \%$ of cases [20]. Tubules and cysts in OCCC may be filled with extracellular mucin [18,20], a feature not present in ccRCC.
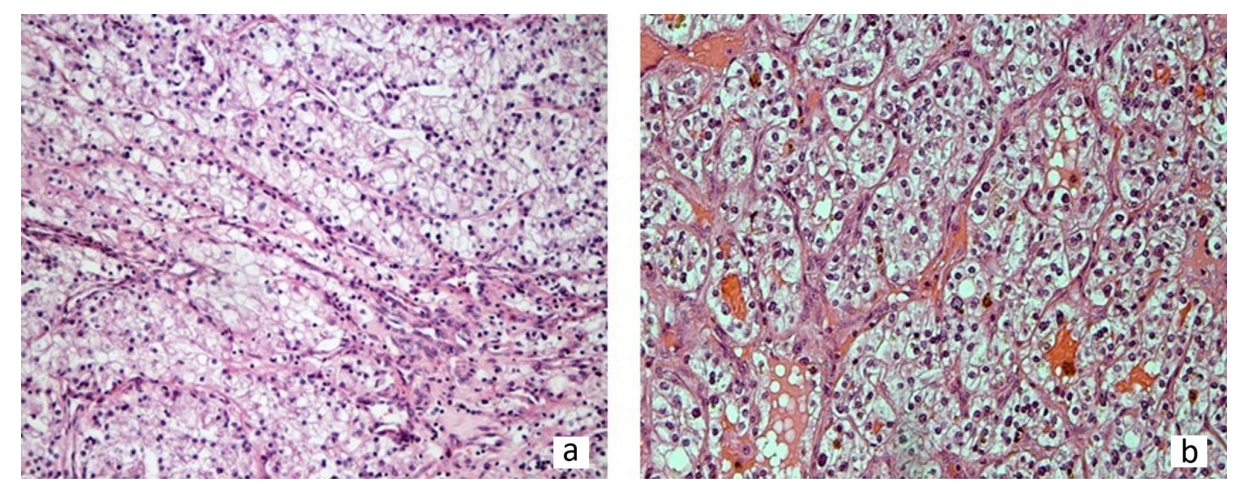


\section{Cureus}

FIGURE 1: (a) ccRCC tumor cells with moderately atypical nuclei lacking significant pleomorphism (H\&E x 100). (b) On higher power magnification, a prominent, thin-walled vascular network is characteristic of CCRCC (H\&E x 200).

ccRCC: clear cell renal cell carcinoma, H\&E: hematoxylin and eosin

Steroid cell tumors not otherwise specified are composed of lipid-rich tumor cells with clear intracytoplasmic vacuoles that are arranged in solid sheets, thin cords, or columns lacking the tubular differentiation of ccRCC which often contain intraluminal blood or colloid-like material [10,21].

Dysgerminomas display a diffuse, trabecular, insular, or cordlike pattern. Tumor cells have large uniform round nuclei and clear cytoplasm. The stroma is filled with numerous mature lymphocytes [21]. The clear cell variant of struma ovarii lacks the characteristic vascular pattern of ccRCC [10].

In difficult cases when ovarian metastasis is the first presentation of the disease, immunohistochemistry can provide diagnostic solutions, and such an approach was followed in 11 of 35 published cases [10-11,21,2627,31-34,36]. Among the most useful immunohistochemical markers are cluster of differentiation (CD)-10 (Figure $2 a$ ) and RCCma (Figure $2 b$ ). The immunohistochemical profile of ccRCC and its ovarian histological mimics is reported in Table 2.
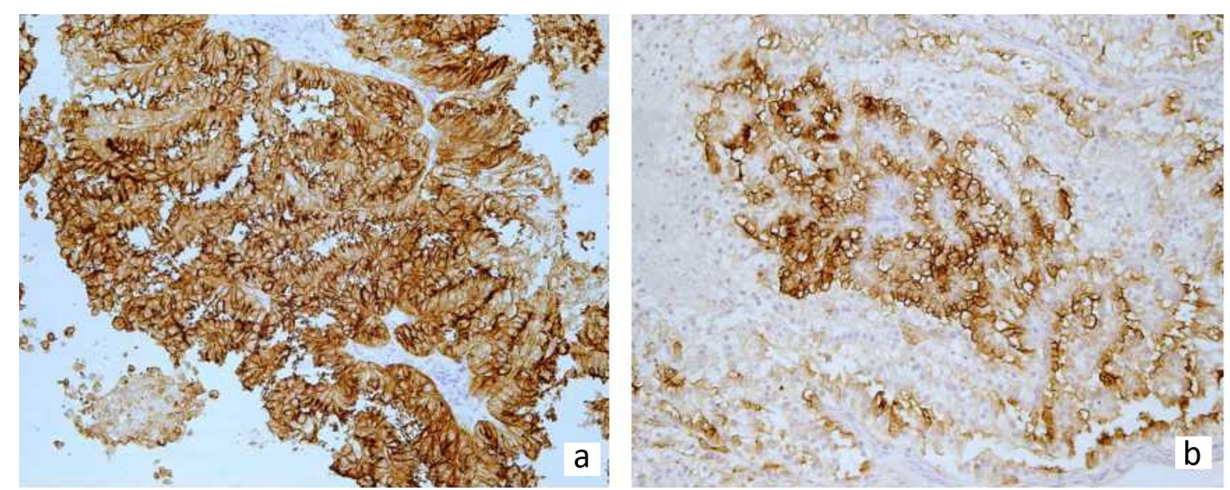

FIGURE 2: (a) CD-10 is usually diffusely positive in ccRCC cells (CD-10 $x$ 200). (b) Tumor cells showing positive staining for RCCma (RCCma $x$ 200)

ccRCC: clear cell renal cell carcinoma, RCCma: renal cell carcinoma marker

Metastatic ccRCC

Steroid cell tumor

Dysgerminoma

\section{TABLE 2: Immunophenotypic profile of clear cell tumors of the ovary}

CK7: cytokeratin 7, EMA: epithelial membrane antigen, OCCC: ovarian clear cell carcinoma, ccRCC: clear renal cell carcinoma, PLAP: placenta alkaline phosphatase, RCCma: renal cell carcinoma marker

In the literature, all 41 patients were treated surgically, 14 with hysterectomy and bilateral salpingooophorectomy (HBSO), four with bilateral salpingo-oophorectomy, two with left salpingo-oophorectomy (LSO), one with right salpingo-oophorectomy, and two with left oophorectomy. In 12 cases, no information 
concerning the type of surgical procedure was provided. Surgical treatment seems to offer a significant benefit in disease-free and overall survival (OS) in metastatic ccRCC. However, in the contemporary era of targeted therapy, cytoreductive nephrectomy or metastasectomy lacks proof of survival benefit with randomized trials [38]. Furthermore, complete resection may be predictive of prolonged os, along with the number of metastatic lesions ( $>1$ lesion), synchronous or asynchronous disease ( $>1$ year from nephrectomy to metastatic disease), site of metastases (pulmonary vs. extrapulmonary), and age (younger vs older than 60 years) [39-40].

Adjuvant therapy was reported in 12 patients in the literature. Eight patients received systemic therapy with interferon-a [19,24], interleukin-2 [22], a combination of interferon-a and sunitinib [27], sunitinib [28], and vinblastine [31]. A patient started treatment with interleukin-2 and continued with a high dose of sunitinib after recurrence. Due to a lack of response, the regimen was altered to everolimus, resulting in no disease progression [30]. In one case, the patient received three cycles of chemotherapy with no further specification [21]. Liang et al. mention four patients receiving chemotherapy without providing more details [34]. Systemic adjuvant therapy was used in our case [36] consisting of the administration of sunitinib initially, later changed to sorafenib, which was stopped two months later due to intolerance and toxicity. Subsequently, pazopanib was administered showing a poor response, followed by nivolumab until the patient succumbed to the disease. Radiotherapy was mentioned in four cases, two of them as palliative therapy for bone [7,29] and brain metastases [9] and in one case for parotid gland, thyroid, and brain metastases [18]. Follow-up was available in 28 patients with the longest period lasting 204 months. Ovarian metastasis is usually part of generalized disease with several patients also having metastases to other organs prior to, concurrently, or after ovarian involvement. The most frequent metastatic sites were, by descending order, bone in five cases $[7,10,17,24,30]$, lung in four cases $[7,13,24]$, abdomen in four cases $[10,13,22,30]$, adrenal glands in three cases [27,34], skin in two cases [18,22], muscle in two cases [20,34], thyroid in two cases [9,16], brain in two cases [9,18]; and one metastasis to each of the following organs: parotid [18], liver [34], gallbladder [29], vagina [12], and cervical, pelvic, and paraaortic lymph nodes [7,16,22]. In 12 cases, the ovary was the sole metastatic lesion described. Ten patients died of disease, nine patients were alive with no evidence of disease (ANED), and nine were alive with metastatic disease (AWD) in a period ranging from two months to 17 years (mean: 44 months).

Because there is no consistency in the data reported by different authors, no safe conclusions can be made regarding survival.

Two cases of PRCC ovarian metastasis were found in the literature. Patients' age ranged from 45 to 73 years (mean age: 59 years). The right and left kidneys were involved in one case each. Ovarian metastasis was ipsilateral in one case [35] and contralateral in the second [25]. The primary tumor size ranged from 85 to $106 \mathrm{~mm}$ (mean value: $95.5 \mathrm{~mm}$ ), whereas the size of the metastatic lesion ranged from 60 to $117 \mathrm{~mm}$ (mean value: $88.5 \mathrm{~mm}$ ). Patients presented with abdominal pain, constipation [25], and abdominal mass [35]. Ovarian metastasis was detected 36 months after kidney involvement [25] and concomitantly [35]. Fuhrman grade is mentioned in one case (grade 3). Simultaneous metastatic involvement was present in both cases in the para-aortic lymph nodes [35] and anterior parietal peritoneum [25]. Patients were treated with HBSO [35] and LSO [25]. No other clinical data concerning treatment or follow-up are referred [25] in one case, whereas the other patient did not receive adjuvant therapy and was ANED three months after surgery [35].

Histologically, PRCC may simulate papillary tumors from other locations, including the ovary such as in OCCC and ovarian serous carcinoma [25,34]. In difficult cases, immunohistochemical staining may provide some help. Typical high-grade serous carcinoma is positive for Wilms' tumor 1 (WT-1), and therefore negative staining for WT-1 favors metastatic carcinoma [34].

A single case of metastatic ChRCC to the ovary is described in a case series [34]. A patient with a history of ChRCC presented with bilateral ovarian metastases found on scheduled postoperative imaging. The tumor of the right ovary measured $150 \mathrm{~mm}$, while the one of the left measured $55 \mathrm{~mm}$. No other clinical data were available. ChRCC ovarian metastasis can mimic sex cord-stromal tumors. ChRCC will stain positive for CD117 and negative for estrogen receptor, calretinin, and inhibin [34].

A single case of metastatic CDC to the ovary was found in the English literature. A 79-year-old patient presented with symptoms of pyelonephritis and hypercalcemia. A radical nephrectomy was performed. High-grade malignant cells were found on frozen sections of the lymph nodes and psoas mass. There was also a large mass in the pelvis close to the primary tumor. Pathology showed a CDC. The patient had postoperative complications, dying 27 days after surgery. Metastatic disease to the left ovary was found at autopsy [23]. CDC differentiation from primary ovarian carcinomas may be difficult due to overlapping histological features such as tubulopapillary architecture and hobnailing. Immunohistochemistry may provide little help with cytokeratin (CK)-903, CK-19, Ulex europaeus agglutinin lectin, and vimentin being positive in CDC [5].

Histologically, it had a papillary architecture mimicking ovarian serous carcinoma and was immunopositive for paired box gene 8 (PAX8), vimentin, P504S, P53, and CK20 (focal) and negative for CK7, WT-1, high molecular weight cytokeratin and p63, CK5/6, CD10, and estrogen receptors, supporting the diagnosis of 
RCCU. There was also involvement of the omentum, peritoneum, and abdominal wall. The patient was AWD 22 months after surgery.

\section{Conclusions}

Ovarian metastasis of KC occurs very rarely. Precise diagnosis may occasionally be challenging, but it is essential for the appropriate management. Immunohistochemistry will assist in most cases. Surgery seems to be an effective means to treat KC metastasis, offering a significant benefit in a disease-free and cancerspecific OS in retrospective studies so far. Adjuvant therapy offers significant benefit in disease control or palliation of symptoms.

\section{Additional Information \\ Disclosures}

Conflicts of interest: In compliance with the ICMJE uniform disclosure form, all authors declare the following: Payment/services info: All authors have declared that no financial support was received from any organization for the submitted work. Financial relationships: All authors have declared that they have no financial relationships at present or within the previous three years with any organizations that might have an interest in the submitted work. Other relationships: All authors have declared that there are no other relationships or activities that could appear to have influenced the submitted work.

\section{References}

1. Turan T, Aykan B, Koc S, et al.: Analysis of metastatic ovarian tumors from extragenital primary sites . Tumori. 2006, 92:491-495.

2. Petru E, Pickel H, Heydarfadai M, Lahousen M, Haas J, Schaider H, Tamussino K: Nongenital cancers metastatic to the ovary. Gynecol Oncol. 1992, 44:83-86. 10.1016/0020-7292(92)90803-Q

3. McCluggage WG, Wilkinson N: Metastatic neoplasms involving the ovary: a review with an emphasis on morphological and immunohistochemical features. Histopathology. 2005, 47:231-247. 10.1111/j.13652559.2005.02194.x

4. Vera-Badillo FE, Conde E, Duran I: Chromophobe renal cell carcinoma: a review of an uncommon entity . Int J Urol. 2012, 19:894-900. 10.1111/j.1442-2042.2012.03079.x

5. Fleming S, Amin MB, Storkel S: Tumours of the kidney/collecting duct carcinoma . The 2016 WHO Classification of Tumours of the Urinary System and Male Genital Organs, 4th Edition. Moch H, Humphrey PA, Ulbright TM, Reuter VE (ed): International Agency for Research on Cancer, Lyon; 2016. 29-30.

6. Cheng L, Amin MB, Lopez-Beltran A, Montironi R: Tumours of the kidney/collecting duct carcinoma . The 2016 WHO Classification of Tumours of the Urinary System and Male Genital Organs, 4th Edition. Moch H, Humphrey PA, Ulbright TM, Reuter VE (ed): International Agency for Research on Cancer, Lyon; 2016. 41.

7. Toquero L, Aboumarzouk OM, Abbasi Z: Renal cell carcinoma metastasis to the ovary: a case report . Cases J. 2009, 2:7472. 10.4076/1757-1626-2-7472

8. Fields S, Libson E, Lavie O, Beller U: Renal cell carcinoma metastatic to the ovary ultrasound and CT appearance. Clin Imaging. 1996, 20:42-44. 10.1016/0899-7071(94)00075-1

9. Kostrzewa M, Zyła M, Władziński J, Stetkiewicz T, Stachowiak G, Wilczynski J: Metastases of renal clear cell carcinoma to ovary--case report and review of the literature. Eur J Gynaecol Oncol. 2015, 36:219-222. 10.12892/ejgo2608.2015

10. Insabato L, De Rosa G, Franco R, D’Onofrio V, Di Vizio D: Ovarian metastasis from renal cell carcinoma: a report of three cases. Int J Surg Pathol. 2003, 11:309-312. 10.1177/106689690301100408

11. Ibrahim A, Al-Jafari MS: Metastatic renal cell carcinoma in an ovarian benign mixed mucinous cystadenoma and Brenner tumour: a case report. Case Rep Pathol. 2012, 2012:523231. 10.1155/2012/523231

12. Martzloff $\mathrm{KH}$, Manlove $\mathrm{CH}$ : Vaginal and ovarian metastases from hypernephroma; report of case and review of literature. Surg Gynecol Obstet. 1949, 88:145-154.

13. Hobbs JE, Vorder Bruegge CF, Wegner CR, Wintemute RW: Bilateral ovarian metastases from renal adenocarcinoma; report of a case and discussion of pathogenesis. Obstet Gynecol. 1957, 9:198-205.

14. Stefani P, Selli C, Nicita G, Turini D: Angiographic aspects of renal cell carcinoma metastatic to the female genitalia. Cardiovasc Intervent Radiol. 1981, 4:183-186. 10.1007/BF02552421

15. Buller RE, Braga CA, Tanagho EA, Miller T: Renal-cell carcinoma metastatic to the ovary. A case report . J Reprod Med. 1983, 28:217-220.

16. Young RH, Hart WR: Renal cell carcinoma metastatic to the ovary: a report of three cases emphasizing possible confusion with ovarian clear cell adenocarcinoma. Int J Gynecol Pathol. 1992, 11:96-104. 10.1097/00004347-199204000-00003

17. Liu FS, Ho ES, Lu F, Chang CY: Solitary metastasis of renal cell carcinoma to the ovaries: a case report . Zhonghua Yi Xue Za Zhi (Taipei). 1992, 50:165-168.

18. Spencer JR, Eriksen B, Garnett JE: Metastatic renal tumor presenting as ovarian clear cell carcinoma Urology. 1993, 41:582-584. 10.1016/0090-4295(93)90111-M

19. Adachi Y, Sasagawa I, Nakada T, Saitoh M, Mitobe K, Ohta T, Tanaka M: Bilateral ovarian metastasis from left renal cell carcinoma. Urol Int. 1994, 52:169-171. 10.1159/000282600

20. Vara A, Madrigal B, Veiga M, Diaz A, Garcia J, Calvo J: Bilateral ovarian metastases from renal clear cell carcinoma. Acta Oncol. 1998, 37:379-380. 10.1080/028418698430610

21. Hammock L, Ghorab Z, Gomez-Fernandez CR: Metastatic renal cell carcinoma to the ovary: a case report and discussion of differential diagnoses. Arch Pathol Lab Med. 2003, 127:e123-126.

22. Valappil SV, Toon PG, Anandaram PS: Ovarian metastasis from primary renal cell carcinoma: report of a case and review of literature. Gynecol Oncol. 2004, 94:846-849. 10.1016/j.ygyno.2004.06.035 
23. Kassouf W, Binsaleh S, Cohen DD, Carrier S: Bellini duct carcinoma with ovarian metastasis . Can J Urol. 2004, 11:2461-2462.

24. Kato Y, Numata A, Wada N, Iwata T, Saga Y, Hashimoto H, Kakizaki H: A case of metastatic renal cell carcinoma to the ovary. Hinyokika Kiyo. 2006, 52:923-927.

25. Stolnicu S, Borda A, Radulescu D, Puscasiu L, Berger N, Nogales FF: Metastasis from papillary renal cell carcinoma masquerading as primary ovarian clear cell tumor. Pathol Res Pract. 2007, 203:819-822. 10.1016/j.prp.2007.07.007

26. Albrizio M, La Fianza A, Gorone MSP: Bilateral metachronous ovarian metastases from clear cell renal carcinoma: a case report. Cases J. 2009, 2:7083. 10.1186/1757-1626-2-7083

27. Anagnostou VK, Tiniakos DG, Chorti M, Kiagia M, Tourkantonis I, Alamara C, Syrigos KN: Right sited renal cell carcinoma metastasizing to the contralateral ovary: case report and review of the literature. Pathol Oncol Res. 2009, 15:123-127. 10.1007/s12253-008-9039-7

28. Guney S, Guney N, Ozcan D, Sayilgan T, Ozakin E: Ovarian metastasis of a primary renal cell carcinoma: case report and review of literature. Eur J Gynaecol Oncol. 2010, 31:339-341.

29. Decoene J, Ameye F, Lerut E, Oyen R, Van Poppel H, Joniau S: Renal cell carcinoma with synchronous metastasis to the calcaneus and metachronous metastases to the ovary and gallbladder. Case Rep Med. 2011, 2011:1-4. 10.1155/2011/671645

30. Udoji E, Herts BR: Renal cell carcinoma metastatic to the ovary . J Urol. 2012, 188:603-604. 10.1016/j.juro.2012.05.022

31. Bauerová L, Dundr P, Fischerová D, Pešl M, Zikán M, Burgetová A: Ovarian metastasis of clear cell renal cell carcinoma: a case report. Can Urol Assoc J. 2014, 8:188-192. 10.5489/cuaj.1456

32. Dolanbay M, Kutuk MS, Uludag S, Ozgun MT, Ozturk F, Ozcelik B: A case of renal cell carcinoma with solitary metastasis to the ovary. J Obstet Gynaecol. 2015, 35:218-219. 10.3109/01443615.2014.948814

33. Bohara S, Dey B, Agarwal S, Bharti JN, Khurana N, Sachdeva P: Metastatic renal cell carcinoma masquerading as a primary ovarian mass in a post-operative case of meningioma and renal cell carcinoma. Rare Tumors. 2015, 7:5824. 10.4081/rt.2015.5824

34. Liang L, Huang H, Dadhania V, Zhang J, Zhang M, Liu J: Renal cell carcinoma metastatic to the ovary or fallopian tube: a clinicopathological study of 9 cases. Hum Pathol. 2016, 51:96-102. 10.1016/j.humpath.2015.12.017

35. Bhaskar V, Kumar M, Goel S, Sankhwar S: Papillary renal cell carcinoma with synchronous ovarian metastasis: a rare entity. BMJ Case Rep. 2017. 10.1136/bcr-2017-220764

36. Koufopoulos N, Pigadioti E, Tsouma E, Kosmas K, Khaldi L: Renal cell carcinoma with bilateral ovarian metastasis. Virchows Arch. 2018, 473:77.

37. De Waal YRP, Thomas CMG, Oei ALM, Sweep FC, Massuger LF: Secondary ovarian malignancies: frequency, origin, and characteristics. Int J Gynecol Cancer. 2009, 19:1160-1165.

38. Barata PC, Rini BI: Treatment of renal cell carcinoma: current status and future directions . CA Cancer J Clin. 2017, 67:507-524. 10.3322/caac.21411

39. Kavolius JP, Mastorakos DP, Pavlovich C, Russo P, Burt ME, Brady MS: Resection of metastatic renal cell carcinoma. J Clin Oncol. 1998, 16:2261-2266. 10.1200/JCO.1998.16.6.2261

40. Alt AL, Boorjian SA, Lohse CM, Costello BA, Leibovich BC, Blute ML: Survival after complete surgical resection of multiple metastases from renal cell carcinoma. Cancer. 2011, 117:2873-2882. $10.1002 /$ cncr.25836 